\title{
Distribution of seahorse species in Malaysia, harvesting trends and conservation concerns - A review
}

\author{
Chen Cheng Ann'1, Nur Fatihah Abd Halid1*, Adam Lim Chee 0oi'2, Annie Christianus ${ }^{3,4}$ and Rossita \\ Shapawi ${ }^{1}$ \\ 1 Borneo Marine Research Institute, Universiti Malaysia Sabah, Jalan UMS, 88400 Kota Kinabalu, Sabah Malaysia \\ ${ }^{2}$ Save Our Seahorses Malaysia, 46000 Petaling Jaya, Selangor, Malaysia \\ 3 Institute of Bioscience, University Putra Malaysia, 43400 Serdang, Selangor, Malaysia \\ ${ }^{4}$ Department of Aquaculture, Faculty of Agriculture, University Putra Malaysia, 43400 Serdang, Selangor, \\ Malaysia
}

*Corresponding author: fatihahhalid@ums.edu.my

\begin{abstract}
Seahorse is a unique fish belonging to the genus Hippocampus. It has a horse-like head, tubular mouth, and the body is covered with rings of armoured plates until the tip of the prehensile tail. Seahorses are traded for human consumption and ornamental purposes. However, the dry product of seahorses has a major demand for traditional Chinese medicine (TCM). The ornamental products such as keychains, earrings and brooches also support a growing 'curio' trade. There is a limited amount of published data on seahorse distribution in Malaysia despite increasing pressure of exploitation, this study was carried out to review the available information, identify knowledge gaps and draw attention towards sustainability of the seahorse populations. To date, twelve seahorse species have been reported in Malaysia. Most of these species are found in East Malaysia. In Sabah, 11 out of 12 tropical seahorse species have been encountered. This does not include the Japanese dwarf seahorse, Hippocampus mohnikei. Among the eleven species of seahorses found in Sabah are seven species of common size seahorses, H. barbouri, H. comes, H. histrix, H. kelloggi, H. kuda, H. spinosissimus and H. trimaculatus and four species of pygmy seahorses, H. bargibanti, H. denise, H. satomiae and H. pontohi, that were previously identified as $H$. severnsi. This study highlights the importance of conservation of wild population of seahorses and the need for farming as a means of lessening the exploitation of wild stocks while meeting the human demand.
\end{abstract}

Keywords: Seahorses, Species distribution, Overexploitation, Knowledge gaps, Sustainability concerns

\section{Introduction}

The seahorses belong to the genus Hippocampus. This fish has a horse-like head, tubular mouth, and its bony plates arranged in articulated ring-like segments throughout body up to the tip of the prehensile tail (Porter et al., 2013). Seahorses of the family of Syngnathidae are placed together with seadragon, pipefish and pipehorse (Porter et al., 2013; Blanco and Planas, 2015). Syngnathid fish are known to be slow swimmers. Their swimming behaviour is highly specialized involving rapid oscillation of the dorsal fin due to the absence of caudal fin and whole caudal region (Ashley-Ross, 2002). Only seahorses swim upright, while the rest keep their bodies in a horizontal position (Kuiter, 2009; Neutens et al., 2014). Seahorse is well known to exhibit male parental care with the presence of brood pouch upon maturity to carry the eggs contributed by the female parent (Planas et al., 2010; Dudley et al., 2021).
Globally, 46 species of seahorses have been described so far (Koldewey and Martin-Smith, 2010; O'Donnell et al., 2010). Out of the 12 seahorse species found in Malaysia, 11 have been reported from Sabah but the presence of Hippocampus mohnikei (Lim et al., 2011; Aylesworth et al., 2016; Lourie et al., 2016) has not been confirmed. Both dwarf and pygmy seahorses are smallsized fish that begin reproducing when 1-2 inch in height (Kanuo and Kohno, 2001; Shepherd et al., 2017). The brood pouch is still prominent in male dwarf seahorses at the tail region whereas pygmy seahorses have trunk brooding habit (Smith and Tibbetts, 2008). Among the 11 species of seahorses in Sabah the most common are $H$. barbouri, $H$. comes, $H$. histrix, $H$. kelloggi, $H$. kuda, $H$. spinosissimus and $H$. trimaculatus in addition to 4 species of pygmy seahorse, $H$. bargibanti, $H$. denise, $H$. satomiae and $H$. pontohi, that were previously identified as $H$. severnsi (Lim et al., 2011; Lourie et al., 2016). Figure 1 shows 12 seahorse species reported in Malaysia. 
a

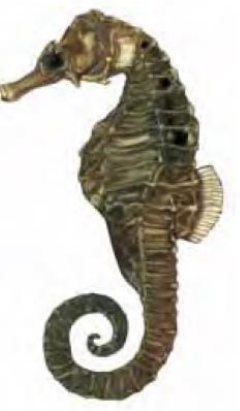

g

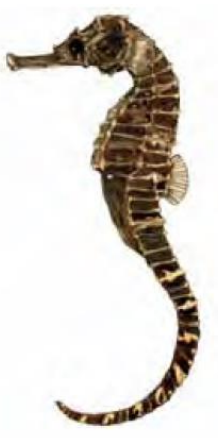

b

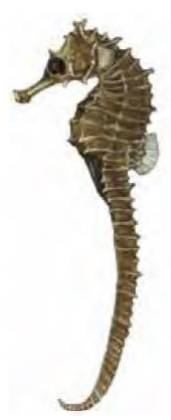

h

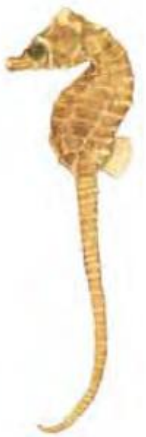

C

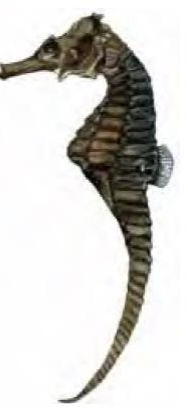

d

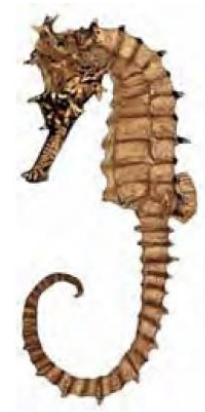

e
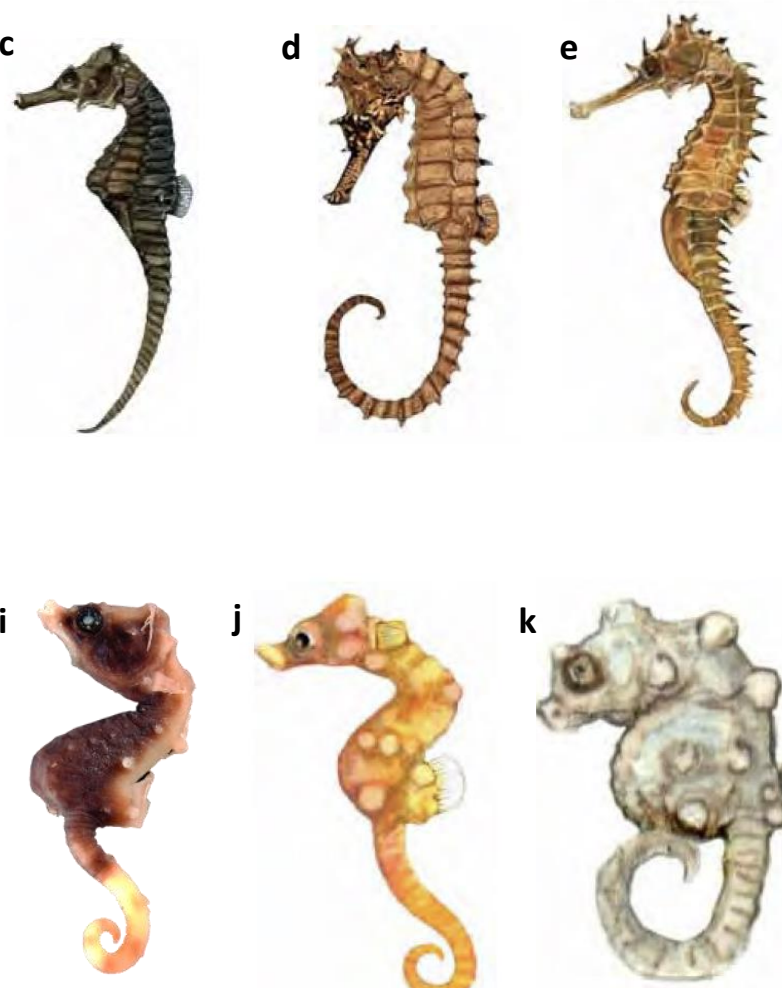

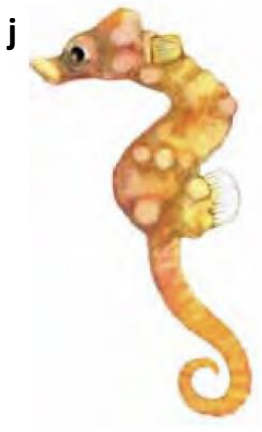

k

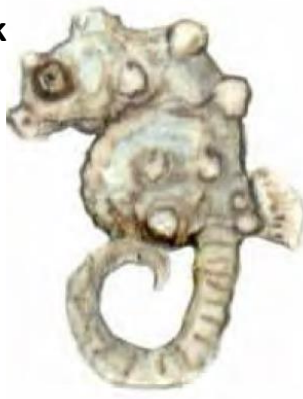

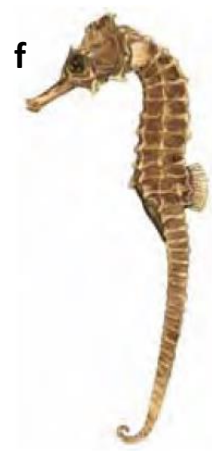

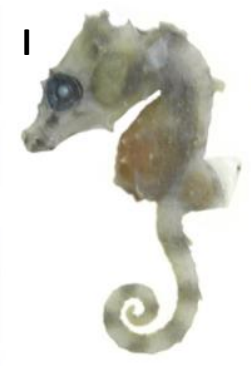

Figure 1. Seahorse species in Malaysia (a) Hippocampus trimaculatus, (b) H. spinosissimus, (c) H. kuda, (d) H. barbouri, (e) H. histrix, (f) H. kelloggi, (g) H. comes, (h) H. mohnikei, (i) H. pontohi, (j) H. denise, (k) H. bargibanti and (l) H. satomiae. Source: Lourie et al. (2004), Lourie and Kuiter (2008)

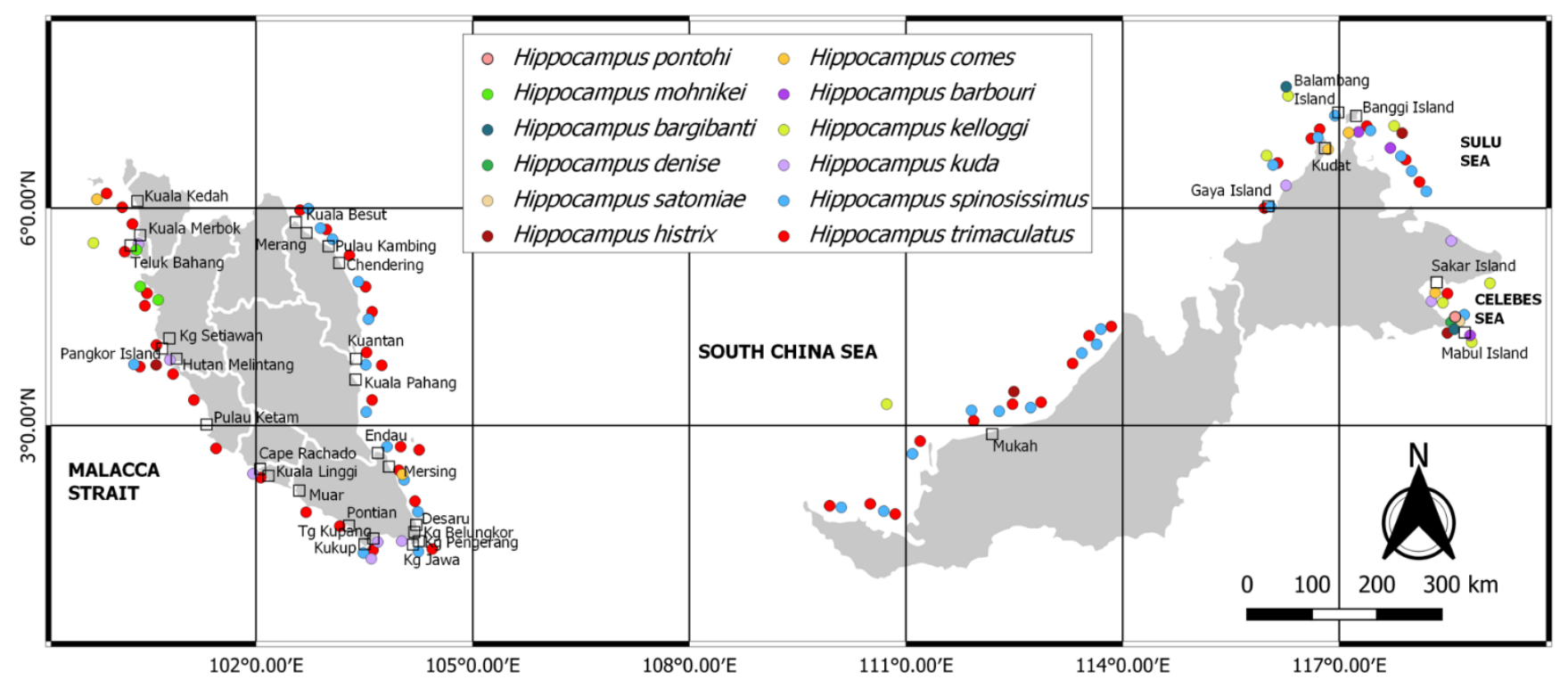

Figure 2. Distribution of seahorse species in Peninsular Malaysia (Source: Choo and Liew, 2003; 2004; Lim et al., 2011; Shapawi et al., 2015; Aylesworth et al., 2016; Wong and Teh, 2017) 


\section{Habitat and distribution of seahorses in Malaysia}

Seahorses are found in shallow coastal waters of temperate and tropical regions less than $150 \mathrm{~m}$ deep, with the greatest diversity recorded in the Indo-Pacific (Lourie et al., 2004). Even seahorse that are known as marine species, it is possible to find some species such $H$. abdominalis, $H$. capensis, $H$. kuda, or $H$. reidi in habitats with fluctuating salinities such as estuaries or lagoons (Choo and Liew, 2004; Martin-Smith and Vincent, 2005; Dody et al., 2021). Water currents and holdfast facilities might influence the distribution of these slow swimmer seahorses (Correia et al., 2018). Seahorses usually use their prehensile tail to attach to the corals, mangrove roots, seagrasses and sponges in the muddy, sandy or rocky areas (Lourie et al., 2005; Martin-Smith and Vincent, 2005). Seahorses have also been observed attached to artificial structures in jetties or mussel farms (Kuiter, 2000). Distribution of seahorse species in Malaysia is shown in Figure 2.

The most frequently found species in Malaysia, $H$. trimaculatus, is present throughout the coastal waters of the country. It is also associated with $H$. spinosissimus on the east coast of Peninsular Malaysia, but on the west coast, $H$. spinosissimus, was found only in Pangkor Island (Choo and Liew, 2003). In East Malaysia, both the species are widely distributed in the waters along the coast of South China Sea, Sulu Sea and Celebes Sea, at 20-40 m depth of gorgonians-sea whip beds (Choo and Liew, 2004). Sand bottom is the preferable habitat for these species, with $H$. spinosissimus commonly associated with soft corals (Lim et al., 2011; Shapawi et al., 2015). In 2017, H. trimaculatus was observed drifting near the water surface of Port Dickson (Negeri Sembilan), indicating translocation and long-distance dispersal from deeper areas and demersal habitats (Wong and Teh, 2017).

H. kelloggi, it is exclusively found in Tukun Perak Island, Peninsular Malaysia, at 65-90 m (Choo and Liew, 2003). While in East Malaysia, H. kelloggi also appeared on gorgonian beds of South China Sea, Sulu Sea and Celebes Sea, in much the same way as H. trimaculatus and H. spinosissimus, but in the deeper (40-80 m) offshore areas (Choo and Liew, 2004). According to Lim et al. (2011), both $H$. comes and $H$. histrix were discovered earlier in East Malaysia than in Peninsular Malaysia. Hippocampus histrix is considered scarce since they are only found in certain areas like Jarak Island in Peninsular Malaysia, Mukah in Sarawak, Banggi Island and Semporna Island in Sabah (Choo and Liew, 2004; Lim et al., 2011). The habitat for $H$. histrix in Malaysia remains unclear as it was only caught by trawlers together with $H$. trimaculatus and $H$. spinosissimus from deeper areas (Choo and Liew;
2004). However, Lim et al. (2011) believed that $H$. histrix populated the Halimeda beds and was potentially associated with seagrasses. Hippocampus comes is found in Langkawi and Mersing Islands in Peninsular Malaysia, whereas in Kudat, Banggi Island and Sakar Island in East Malaysia it is seen associated with either the hard coral reef, sponges, seagrasses or seaweeds such as Sargassum sp. at about $2 \mathrm{~m}$ depth (Lim et al., 2011; Choo and Liew, 2004). Besides, $H$. comes was found near the Jetty of Universiti Malaysia Sabah (UMS), Kota Kinabalu (Shapawi et al., 2015).

The existence of $H$. kuda has been reported from specific places on the west and south coasts of Peninsular Malaysia, like Kuala Merbok, Dinding River, Cape Rachado, Johor River, Pulai River and Kuala Skudai (Choo and Liew, 2003; Lim et al., 2011). It is also found in Sandakan, Gaya Island, Balambangan Island and Sakar Island, Sabah (Choo and Liew, 2004, Lourie et al., 2005). Usually, $H$. kuda can be found attached to seagrass, Enhalus sp. either in river mouths or estuaries with depth between 1-3 m. In East Malaysia, H. kuda sometimes occurs in beds of $H$. barbouri in Halimeda (Choo and Liew, 2004; Lim et al., 2011). Neither of these has been reported from Sarawak waters. Both $H$. kuda and H. barbouri also occur around the UMS Jetty, Kota Kinabalu (Shapawi et al., 2015). At Gaya Island, Balambangan Island, Tanjung Aru, Banggi Island and Mabul Island, H. barbouri is also reported in Halimeda beds and in shallow and sheltered bays (1-2 $\mathrm{m}$ depth) but is only occasionally caught by trawlers at the $20 \mathrm{~m}$ in depth (Choo and Liew, 2004; Shapawi et al., 2015).

Hippocampus barbouri with all the four pygmy seahorses, $H$. bargibanti, $H$. denise, $H$. pontohi and $H$. satomiae, are only reported from the coastal waters of East Malaysia. However, the presence of $H$. pontohi, previously known as $H$. severnsi, in Malaysia, is yet to be confirmed, as only described in anecdotal sources (Lim et al., 2011). Both $H$. denise and $H$. bargibanti are found in Semporna and Spratly Islands, whereas H. satomiae was encountered in Semporna, occupying the gorgonians (sea fans) area in depth between 12-25 m (Lourie and Randall, 2003; Lourie and Kuiter, 2008; Lim et al., 2011). Unlike the pygmy seahorse, $H$. mohnikei, is the only species of dwarf seahorse that can be found in mangrove and seagrass areas (1-6 m depth) of Kuala Gula, Sepetang and Bagan Dalam (Aylesworth et al., 2016). Figure 3 illustrates the potential habitat and average depth segregations in the coastal waters of Malaysia, from the shallow estuaries (1-3 m) all the way up to deep-waters associated with gorgonians $(<95 \mathrm{~m})$. Different findings described various habitat and depth segregations of the 11 seahorse species in Malaysia. 


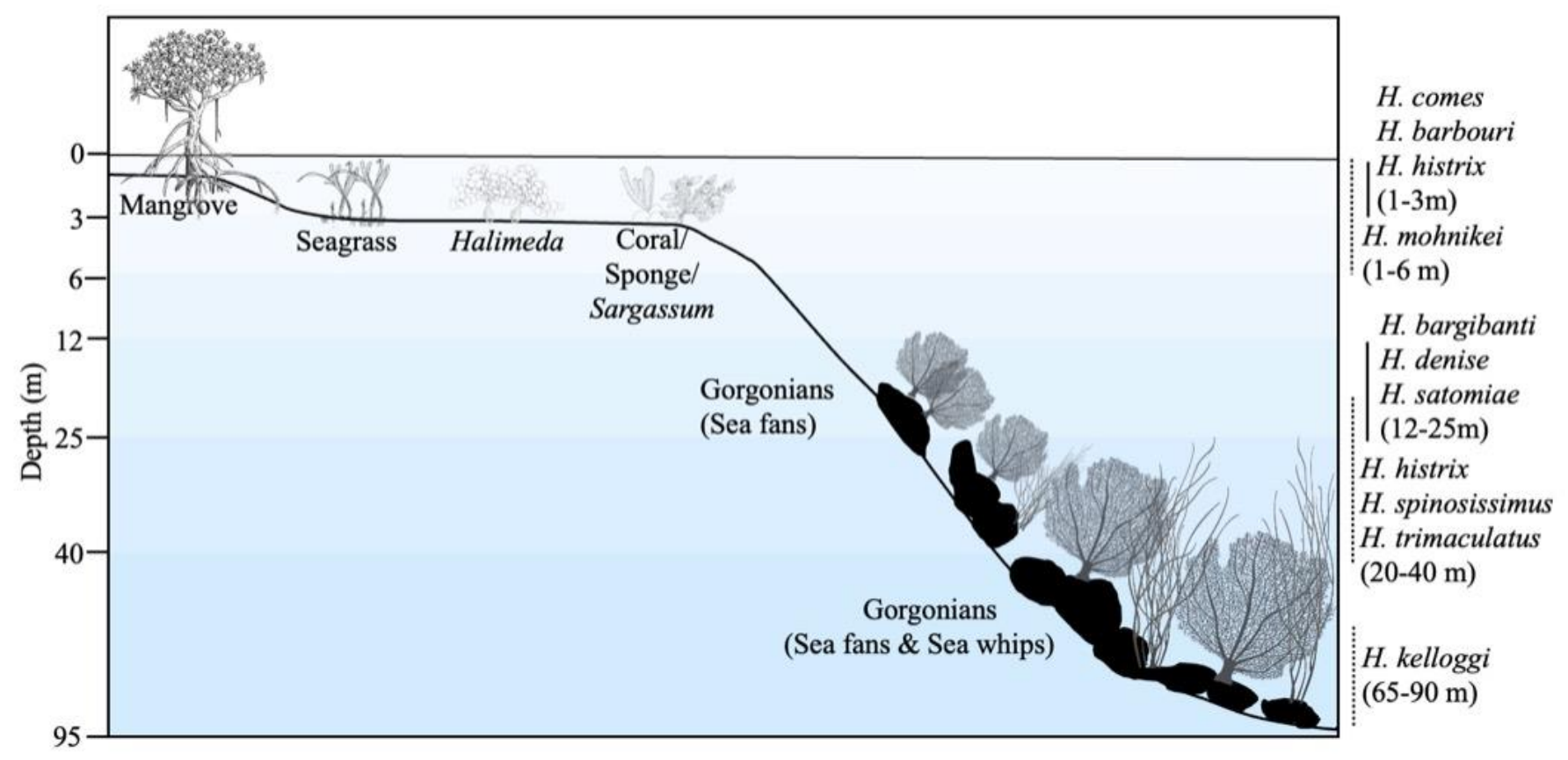

Figure 3. Potential habitat and average depth segregations of eleven seahorse species in water of Malaysia (Source: Choo and Liew, 2003; Liew, 2004; Lim et al., 2011; Aylesworth et al., 2016)

\section{Conservation}

About ten million seahorses sourced from the wild population were traded every year between 80 countries to meet the demands for traditional Chinese medicine (TCM), aquarium industry and souvenir (also known as 'curio') trade (Vincent et al., 2014). Most of the catch is sold for TCM (Vincent et al., 2011). All the species of seahorse are used in TCM since it is believed to enhance energy flows in the body, healing effects on health problems, for example, asthma, high cholesterol, goiter, kidney malfunction and skin problems such as acne and nodules. Scientific literature only described the therapeutic value as antitumor and antiaging effects, without any clinical trials (Zhang et al., 2017). Seahorse is also required as an ingredient in TCM derivatives in Korea and Japan, known as hanyak and kanpo, respectively, as well in traditional medicine in Indonesia called jamu (Kumaravel et al., 2012). Seahorses used in TCM are typically ground to a powder and encapsulated, applied directly to wounds, or mixed with a liquid (usually warm water). Additionally, sometimes whole seahorses are soaked in alcohol, oil or even prepared in soups (Rosa et al., 2013). Usually, large size seahorse with pale coloration and without bodily spine is the most preferred in TCM (Vincent, 1996). However, processing the catch into powder eliminates the preference for the species, and species such as $H$. barbouri are traded for TCM alongside $H$. spinosissimus, $H$. comes, $H$. kuda and $H$. trimaculatus (Perry et al., 2010). Moreover, seahorses are also commonly used in folk medicines practiced in Africa, India, Philippines and Latin America (Baum and Vincent,
2005; Rosa et al., 2013). In Brazil, seahorses are commonly traded for medicinal purposes (Rosa, 2005; Alves and Rosa, 2010). They are also known as the most flexible fish species for therapeutic indications (Rosa et al., 2013).

As mentioned earlier, besides TCM, the dried seahorse is also sold for curio trade, that includes products such as keychain or ornaments such as earrings and brooches (Vincent, 1996; Grey et al., 2005; Alves et al., 2006). Curio trade for 65000 seahorses was valued at USD 10000 yearly (Grey et al., 2005). Dried seahorse product is mainly sourced from Asia and traded among the Asian countries, including Hong Kong, Taiwan, China, Singapore and Japan, besides small quantities being exported to United Kingdom, United States and Australia (Perry et al., 2010; Evanson et al., 2011). In TCM trade, the price of dried seahorse can reach USD $1200 \mathrm{~kg}^{-1}$ (Vincent, 1996; Perry et al., 2010). Ornamental fish hobbyists and public aquaria also demand live seahorses, albeit, in much smaller numbers compared to the quantities in dried product trade (Vincent, 1996). Live seahorses are sourced from Asian countries (Vietnam, Sri Lanka Philippines and Indonesia) for export to North America or European Union, besides Australia, Hong Kong, Japan and Taiwan, which involved up to a million of seahorses annually (Vincent, 1996). For the marine aquarium industry, live seahorse produced in captivity are sold at a price range of USD 60-950 individually, higher compared to USD 1-80 individually for seahorse sources from wild-caught. (Vincent et al., 2011). 
Small numbers of seahorses come from subsistence fishermen in developing countries caught either by hand during diving or using dip-nets from rafts in waist-deep water (Vincent, 1996; Martin-Smith et al., 2004; Rosa et al., 2006). Almost $95 \%$ of seahorses traded were sourced either directly or as bycatch from shrimp trawling. Seahorses live in the same zone as shrimp (demersal mode), and due to slow swimming behaviour and mesh size (Martin-Smith and Vincent, 2006; Vincent et al., 2011) they are caught in bulk quantities. Although only small proportions of seahorses are caught by individual vessels, the cumulative number of seahorse bycatch annually is large. In Vietnam alone, the recorded catch was 1-2 seahorse(s) vessel-1 day $^{-1}$ but the total annual catch reached up to 6.5 tonnes, consisting of about 2.2 million seahorses (Giles et al., 2006). Few countries bring a significant number of seahorse bycatch through shrimp trawlers, including Malaysia. However, trade surveys conducted worldwide indicate a pattern of decline in seahorse landings (Vincent et al., 2011). In Vietnam, seahorse bycatch dropped from $30-60 \%$ within three years, while on the coasts of Pacific and Atlantic Oceans, seahorse bycatch reduced more than $75 \%$, and in Malaysia, the decrease was about 70\% (Baum et al., 2003; Giles et al., 2006; Perry et al., 2010). Besides seahorse bycatch, coastal developments also threaten the seahorse population due to degradation or loss of seahorse habitats. For example, extensive port development in Pulai Estuary in Malaysia destroyed the seagrass meadows and reduced the numbers of $H$. kuda (Sabri, 2009). The destruction of seagrass habitats during the construction of a nearby marina also resulted in decline of $H$. zosterae population in Tampa Bay, Florida (Masonjones et al., 2010).

Threat to seahorse population has drawn attention towards conservation measures. Based on the IUCN (2020), the status of seahorse species in Malaysia is listed in Table 1, with eight species as Vulnerable (VU), three species Data Deficient (DD) and only one listed as Least Concern (LC). The VU status is due to their sparse distribution, low mobility, small home ranges, low fecundity, lengthy parental care, and mate fidelity, which make them vulnerable to overfishing and habitat damage (Foster and Vincent, 2004). The DD indicates that more information is needed to improve the understanding of biology and ecology (Planas et al., 2021). Despite the lack of population data, species with no known threats can be classified as LC (Pollom et al., 2021). In 2002, all seahorse species were listed in Appendix II of CITES (Convention for the International Trade in Endangered Species of Wild Fauna and Flora), implemented in 2004 (CITES, 2002). This requires all CITES Parties to ensure that the international trade does not adversely affect wild populations. Since then, aquaculture has been developed to ensure the sustainability of the seahorse trade (Job, 2005).

Table 1. List of seahorses, Hippocampus sp. in Malaysia with morphology description, locality, habitat preferences and IUCN status.

\begin{tabular}{|c|c|c|c|c|c|}
\hline No. Species & $\begin{array}{l}\text { Morphology } \\
\text { description }\end{array}$ & Locality & Habitat & $\begin{array}{c}\text { IUCN } \\
\text { status }\end{array}$ & References \\
\hline 1. H. barbouri & $\begin{array}{l}\text { White to pale yellow to } \\
\text { pale brown body color, } \\
\text { strips on snout, } \\
\text { sometimes with fine } \\
\text { line radiating from eye. } \\
\text { Well-developed spines } \\
\text { on body with longer } 1^{\text {st }} \\
\text { dorsal spine, regular } \\
\text { series of long and short } \\
\text { tail spine, Single eye } \\
\text { and nose spine, double } \\
\text { cheek spine. }\end{array}$ & $\begin{array}{l}\text { Sabah-Gaya } \\
\text { Island, } \\
\text { Balambangan } \\
\text { Island, Banggi } \\
\text { Island, Mabul } \\
\text { Island, Tanjung } \\
\text { Aru and UMS Jetty }\end{array}$ & $\begin{array}{l}\text { Seaweeds- } \\
\text { Halimeda sp. }\end{array}$ & VU & $\begin{array}{c}\text { Choo and Liew (2004), } \\
\text { Lim et al. (2011), } \\
\text { Shapawi et al. (2015) }\end{array}$ \\
\hline
\end{tabular}

Body color-pale grey or purple with pink or red tubercles, yellow with

2. H. bargibanti orange tubercles.

Bulbous tubercles and Spramporna

scattered over body

and tail. Single eye and

cheek spine. 
Black and yellow in color, alternating along the tail. Smooth to rather spiny body.

3. H. comes Sharp and curved backward eye spine, double cheek spine. Dark bands surround eye socket.
Kedah-Langkawi; Johor-Mersing Island; SabahKudat, Sakar Island, Banggi Island and UMS Jetty
Hard coral, sponges, seagrasses or seaweedsVU Choo and Liew (2004), Lim et al. (2011), Shapawi et al. (2015)
Plain orange color with limited number of tubercles on body and slightly darker rings around tail
Sabah-Semporna and Spratly Island
Gorgonians (sea fans)
DD Lim et al. (2011)

Whitish body-color with long, sharp, pointed and darktipped spines. Single

5. H. histrix eye and nose spines. Banggi Island and Long and slender Semporna Island;

Choo and Liew (2004), Lim et al. (2011)
SeaweedsHalimeda sp.
VU Sarawak-Mukah short in comparison to body length.

Pale yellow with often black or dark brown body color. Thick body rings with smooth or 6. H. kelloggi slightly raised spines on body. Prominent spine above eye, single knob-like and rounded cheek spine.

\section{Perak-Tukun}

Perak Island;

Sabah and

Sarawak-deeper

offshore water

\section{Gorgonians (sea whip)}

VU

Choo and Liew (2003, 2004)
Kedah-Kuala

Merbok; Perak-

Dinding river,

Melaka-Cape

Black to yellow, pale Rachado; yellow color with fairly Johor-Johor River, Seagrass-Enhalus

7. H. kuda dark spots on body. Pulai River and Low spines, only rounded bumps.
Kuala Skudai;

Sabah-UMS Jetty,

Gaya Island,

Balambangan

Island, Sakar

Island, Sandakan 
Dark brown body color. Double cheek spine, double below eye

8. H. mohnikei spine. Some enlargement on specific trunk or tail ring. Tail long in comparison to body length.
Perak-Kuala Gula, Sepetang:- Mangrove and Penang-Bagan seagrass, Enhalus Dalam
VU acoroides
Aylesworth et al. (2016)

Brown body color with large red patch covering, pale tail.

9. H. pontohi White dots scattered on the head, trunk and

Only anecdotal report on the presence
LC

Lim et al. (2011) tail. Single eye, nose and cheek spines.

White to pale brown or greyish body color.

10. H. satomiae Double eye spine, single nose and cheek Sabah-Semporna Gorgonians (sea fans) spine.

Yellow, brown, pale, purplish-grey body color, darker saddle across the dorsal- Perak-Pangkor lateral surface. Sharp Island; East coast and well-developed of Peninsular Soft coral, sandy spines: longer $1^{\text {st }}, 4^{\text {th }}$, Malaysia; coast of bottom, gorgonians (sea whip) Choo and Liew (2003, 2004),

11. H. spinosissimus Sabah and spines; single above Sarawak eye spine; single/double cheek spine.

Black, brown, yellow, pale white, golden orange body color with rarely large dark spot

Coast of Peninsular on $1^{\text {st }}, 4^{\text {th }}$ and $7^{\text {th }}$ trunk Malaysia; coast of rings. Smooth body with pointed backward eye spine and hook-like Sabah and Sarawak
Choo and Liew (2003, 2004),
Sandy bottom, gorgonians (sea whip)
VU Lim et al. (2011), Wong and Teh (2017) cheek spine.

IUCN status: $\mathrm{LC}=$ Least concern, $\mathrm{DD}=$ Data deficient, $\mathrm{VU}=$ Vulnerable

Morphology description referring to Lourie et al. (2004), Lourie and Kuiter (2008) 
The proportion of cultured seahorses in the aquarium trade increased rapidly after their listing in CITES. However, the industry is still struggling to produce adequate numbers of juveniles for farming. The economic viability of captive breeding is technically challenging in terms of diet and healthcare (Pollom et al., 2021; Cohen et al., 2017). The success of seahorse aquaculture will largely depend on its ability to provide an alternative livelihood. Currently, the number of enterprises producing seahorse on a commercial scale for aquaculture industry worldwide is limited (Zhang et al., 2017). Several attempts have been made to cultivate seahorses in Malaysia. The outcome is promising but much remains to be done mainly economizing the farming system and raising healthy stocks to harvestable size for the market.

Limited studies have been conducted on Malaysian seahorses. Perhaps, the first report on seahorse diversity and distribution was published by Choo and Liew $(2003 ; 2004)$. The data was later updated by Lim et al. (2011). There is a paucity of published information on various aspects including population density, sex ratio and home range of Malaysian seahorse in wild population It is important to understand the population dynamics of seahorses sustainable management and conservation purposes (Freret-Meurer and Andreata, 2008). Besides the ecological information, conservation planning and management also requires data on population genetic structure, reproductive dynamics and local adaptations (Garner et al. 2020). The scarcity of genetic data for threatened species impedes assessing genetic diversity that can provide unique insights into population health, demography and persistence (Wilson et al., 2021). Genetic tools have been used to describe new species and reduce misidentification (Koning and Hoeksema, 2021). Traceability of traded seahorses can be improved with the help of cost-effective approaches to identify the harvest from captivity or natural population.

\section{Acknowledgement}

Universiti Malaysia Sabah funded this study through Skim Penyelidikan Pensyarah Lantikan Baru (vot no. SLB2012).

\section{References}

Alves Jr, T. T., Cerqueira, V. R., and Brown, J. A. (2006). Early weaning of fat snook (Centropomus parallelus Poey 1864) larvae. Aquaculture, 253(1-4), 334-342.

Alves, R. R. N., and Rosa, I. L. (2010). Trade of animals used in Brazilian traditional medicine: trends and implications for conservation. Human Ecology, 38(5), 691-704.

Ashley-ross, M. A. (2002). Mechanical properties of the dorsal fin muscle of seahorse (Hippocampus) and pipefish (Syngnathus). Journal of Experimental Zoology, 293(6), 561-577. https://doi.org/10.1002/jez.10183
Aylesworth, L., Lawson, J. M., Laksanawimol, P., Ferber, P., and Loh, T. L. (2016). New records of the Japanese seahorse Hippocampus mohnikei in Southeast Asia lead to updates in range, habitat and threats. Journal of fish biology, 88(4), 1620-1630. https://doi.org/10.1111/jfb.12908

Baum, J. K., Meeuwig, J. J., and Vincent, A. C. (2003). Bycatch of lined seahorses (Hippocampus erectus) in a Gulf of Mexico shrimp trawl fishery. Fishery Bulletin, 101(4), 721-731.

Baum, J. K., and Vincent, A. C. (2005). Magnitude and inferred impacts of the seahorse trade in Latin America. Environmental Conservation, 32(4), 305-319.

Blanco, A., and Planas, M. (2015). Mouth Growth and Prey Selection in Juveniles of the European Long-snouted Seahorse, Hippocampus guttulatus. Journal of the World Aquaculture Society, 46(6), 596-607.

Choo, C. K., and Liew, H. C. (2003). Spatial distribution, substrate assemblages and size composition of sea horses (Family Syngnathidae) in the coastal waters of Peninsular Malaysia. Journal of the Marine Biological Association of the UK, 83(2), 271-276.

Choo, C. K., and Liew, H. C. (2004). A record of seahorse species (family Syngnathidae) in East Malaysia, with notes on their conservation. Malayan Nature Journal, 56(4), 409-420

CITES (2002). Consideration of Proposals for Amendment of Appendices I and II. Twelfth Meeting of the Conference of the Parties: November 2002, Santiago, Chile.

Cohen, F. P., Valenti, W. C., Planas, M., and Calado, R. (2017). Seahorse aquaculture, biology and conservation: knowledge gaps and research opportunities. Reviews in Fisheries Science and Aquaculture, 25(1), 100-111

Correia, M., Koldewey, H. J., Andrade, J. P., Esteves, E., and Palma, J. (2018). Identifying key environmental variables of two seahorse species (Hippocampus guttulatus and Hippocampus hippocampus) in the Ria Formosa lagoon, South Portugal. Environmental Biology of Fishes, 101(9), 1357-1367.

Dody, S., Manuputty, G. D., and Limmon, G. V. (2021). Habitat characteristcs and density of spotted seahorse Hippocampus kuda at waters of Ternate Island and surroundings, Maluku Utara, Indonesia. IOP Conference Series: Earth and Environmental Science, 805(1), 012006.

Dudley, J. S., Hannaford, P., Dowland, S. N., Lindsay, L. A., Thompson, M. B., Murphy, C. R., Van Dyke, J.U., and Whittington, C. M. (2021). Structural changes to the brood pouch of male pregnant seahorses (Hippocampus abdominalis) facilitate exchange between father and embryos. Placenta, 114, 115-123.

Evanson, M., Foster, S., Wiswedel, S., and Vincent, A. (2011). Tracking the international trade of seahorses (Hippocampus species). Fisheries Centre Research Reports, 19(2), 1-94.

Foster, S. J., and Vincent, A. C. J. (2004). Life history and ecology of seahorses: implications for conservation and management. Journal of Fish Biology, 65(1), 1-61.

Freret-Meurer, N. V., and Andreata, J. V. (2008). Field studies of a Brazilian seahorse population, Hippocampus reidi Ginsburg, 1933. Brazilian Archives of Biology and Technology, 51(4), 543-551.

Garner, B. A., Hoban, S., and Luikart, G. (2020). IUCN Red List and the value of integrating genetics. Conservation Genetics, 21(5), 795-801.

Giles, B. G., Ky, T. S., and Vincent, A. C. J. (2006). The catch and trade of seahorses in Vietnam. Biodiversity and Conservation, 15(8), 24972513.

Grey, M., Blais, A. M., and Vincent, A. C. (2005). Magnitude and trends of marine fish curio imports to the USA. Oryx, 39(4), 413-420.

IUCN (2020) The IUCN Red List of Threatened Species Version 2020-1: http://www.iucnredlist.org. Downloaded on 28 December 2020. 
Job, S. (2005). Integrating marine conservation and sustainable development: Community-based aquaculture of marine aquarium fish. Live Reef Fish Information Bulletin, 13, 24-29.

Kanou, K., and Kohno, H. (2001). Early life history of a seahorse, Hippocampus mohnikei, in Tokyo Bay, Japan. Ichthyological Research, 48(4), 361-368.

Koldewey, H. J., and Martin-Smith, K. M. (2010). A global review of seahorse aquaculture. Aquaculture, 302(3), 131-152.

Koning, S., and Hoeksema, B. W. (2021). Diversity of Seahorse Species (Hippocampus spp.) in the International Aquarium Trade. Diversity, 13(5), 187.

Kuiter, R. H. (2000). Seahorses, Pipefishes and their Relatives: A Comprehensive Guide to Syngnathiformes. Chorleywood: TMC Publishing.

Kuiter, R. H. (2009). Seahorses and their Relatives. Victoria: Aquatic Photographics.

Kumaravel, K., Ravichandran, S., Balasubramanian, T., and Sonneschein, L. (2012). Seahorses - A source of traditional medicine. Natural Product Research, 26(24), 2330-2334.

Lim, A. C. O., Chong, V. C., Wong, C. S., and Choo, C. K. (2011). Diversity, habitats and conservation threats of syngnathid (Syngnathidae) fishes in Malaysia. Tropical Zoology, 24(2), 193-222.

Lourie, S. A., Foster, S. J., Cooper, E. W., and Vincent, A. C. (2004). A Guide to the Identification of Seahorses. Washington: University of British Columbia and World Wildlife Fund.

Lourie, S. A., Green, D. M., and Vincent, A. C. J. (2005). Dispersal, habitat differences, and comparative phylogeography of Southeast Asian seahorses (Syngnathidae: Hippocampus). Molecular Ecology, 14(4), 1073-1094.

Lourie, S. A., Pollom, R. A., and Foster, S. J. (2016). A global revision of the seahorses Hippocampus Rafinesque 1810 (Actinopterygii: Syngnathiformes): taxonomy and biogeography with recommendations for further research. Zootaxa, 4146(1), 1-66.

Lourie, S. A., and Kuiter, R. H. (2008). Three new pygmy seahorse species from Indonesia (Teleostei: Syngnathidae: Hippocampus). Zootaxa, 1963(1), 54-68.

Lourie, S. A., and Randall, J. E. (2003). A new pygmy seahorse, Hippocampus denise (Teleostei Syngnathidae) from the Indo-Pacific. Zoological Studies, 42(2), 284-291.

Martin-Smith, K. M., and Vincent, A. C. (2006). Exploitation and trade of Australian seahorses, pipehorses, sea dragons and pipefishes (family Syngnathidae). Oryx, 40(2), 141-151.

Martin-Smith, K. M., and Vincent, A. C. J. (2005). Seahorse declines in the Derwent estuary, Tasmania in the absence of fishing pressure. Biological Conservation, 123(4), 533-545.

Masonjones, H. D., Rose, E., McRae, L. B., and Dixson, D. L. (2010). An examination of the population dynamics of syngnathid fishes within Tampa Bay, Florida, USA. Current Zoology, 56(1), 118-133.

Neutens, C., Adriaens, D., Christiaens, J., De Kegel, B., Dierick, M., Boistel, R., and Van Hoorebeke, L. (2014). Grasping convergent evolution in syngnathids: a unique tale of tails. Journal of anatomy, 224(6), 710723.

O'Donnell, K., Pajaro, M., and Vincent, A. (2010). How does the accuracy of fisher knowledge affect seahorse conservation status? Animal Conservation, 13(6), 526-533

Perry, A. L., Lunn, K. E., and Vincent, A. C. J. (2010). Fisheries, largescale trade, and conservation of seahorses in Malaysia and Thailand. Aquatic Conservation: Marine and Freshwater Ecosystems, 20(4), 464-475.
Planas, M., Piñeiro-Corbeira, C., Bouza, C., Castejón-Silvo, I., Vera, M., Regueira, M., Ochoa, V., Bárbara, I., Terrados, J., Chamorro, A., Barreiro, R., Hernández-Urcera, J., Alejo, I., Nombela, M., García, M. E., Pardo, B. G., Peña, V., Díaz-Tapia, P., Cremades, J., and Morales-Nin, B. (2021). A multidisciplinary approach to identify priority areas for the monitoring of a vulnerable family of fishes in Spanish Marine National Parks. BMC Ecology and Evolution, 21(1), 1-20.

Planas, M., Quintas, P., Chamorro, A., and Silva, C. (2010). Female maturation, egg characteristics and fatty acids profile in the seahorse Hippocampus guttulatus. Animal Reproduction Science, 122(1), 66-73.

Pollom, R. A., Ralph, G. M., Pollock, C. M., and Vincent, A. C. (2021). Global extinction risk for seahorses, pipefishes and their near relatives (Syngnathiformes). Oryx, 55(4), 497-506.

Porter, M. M., Novitskaya, E., Castro-Cese.a, A. B., Meyers, M. A., and McKittrick, J. (2013). Highly deformable bones: Unusual deformation mechanisms of seahorse armor. Acta Biomaterialia, 9(6), 6763-6770.

Rosa, I. L., Defavari, G. R., Alves, R. R. N., and Oliveira, T. P. R. (2013). Seahorses in traditional medicines: a global overview. Animals in traditional folk medicine, 207-240.

Rosa, I. L., Sampaio, C. L., and Barros, A. T. (2006). Collaborative monitoring of the ornamental trade of seahorses and pipefishes (Teleostei: Syngnathidae) in Brazil: Bahia State as a case study. Neotropical Ichthyology, 4(2), 247-252.

Rosa, I. M., Alves, R. R., Bonifacio, K. M., Mourao, J. S., Osorio, F. M., Oliveira T. P., and Nottingham, M. C. (2005). Fishers' knowledge and seahorse conservation in Brazil. Journal of Ethnobiology and Ethnomedicine, 1(1), 1-15.

Sabri, S. (2009). Impact of water quality on seagrass meadow at Tanjung Kupang, MSc Thesis, Universiti Teknologi Malaysia.

Shapawi, R., Anyie, A. L., Hussien, M. A. S., and Zuldin, W. H. (2015). Species and Size Composition of Seahorses (genus Hippocampus, family Syngnathidae) in the coastal waters and local market of Kota Kinabalu, Sabah, Malaysia. Tropical life sciences research, 26(2), 1.

Shepherd, B., Wandell, M., and Ross, R. (2017). Mating, birth, larval development and settlement of Bargibant's pygmy seahorse, Hippocampus bargibanti (Syngnathidae), in aquaria. Aquaculture, Aquarium, Conservation and Legislation, 10(5), 1049-1063.

Smith, R. E., and Tibbetts, I. R. (2008). Mating and birth of Denise's pygmy seahorses (Hippocampus denise) observed in the wild. Coral Reefs, 27(3), 617-617.

Vincent, A. C. (1996). The International Trade in Seahorses. Cambridge: TRAFFIC International.

Vincent, A. C., Foster, S., and Koldewey, H. (2011). Conservation and management of seahorses and other Syngnathidae. Journal of Fish Biology, 78(6), 1681-1724.

Vincent, A. C., Sadovy de Mitcheson, Y. J., Fowler, S. L., and Lieberman, S. (2014). The role of CITES in the conservation of marine fishes subject to international trade. Fish and Fisheries, 15(4), 563592 .

Wilson, A. B., Ashe, J., Padron, M., and Hamilton, H. (2021). Comprehensive genus-wide screening of seahorse microsatellite loci identifies priority species for conservation assessment. Conservation Genetics Resources, 13(2), 221-230.

Wong, N. L. W. S., and Teh, J. C. (2017). Direct observation of drifting juvenile seahorse Hippocampus trimaculatus (Leach, 1814) beneath the offshore surface at Malacca Strait. Check List, 13(6), 993.

Zhang, Y. Y., Ryu, B. M., and Qian, Z. J. (2017). A review-biology, aquaculture and medical use of seahorse, Hippocampus spp. Annual Research and Review in Biology, 1-12. 